\title{
Attitudes Towards COVID-19 Vaccine: A Survey of Health Care Workers in Oman
}

\author{
Faryal Khamis ${ }^{1}$ - Abdallah Badahdah ${ }^{2} \cdot$ Nawal Al Mahyijari $^{3} \cdot$ Furqan Al Lawati $^{4} \cdot$ Jaleela Al Noamani $^{5}$. \\ Issa Al Salmi ${ }^{1} \cdot$ Maher Al Bahrani $^{6}$
}

Received: 9 May 2021 / Accepted: 14 November 2021 / Published online: 20 December 2021

(c) The Author(s) 2021

\begin{abstract}
Coronavirus Disease 2019 (COVID-19) vaccine hesitancy among health care workers (HCWs) is widely reported. Here we report on the prevalence of vaccine hesitancy and the factors associated with it in a sample of non-vaccinated HCWs. Data from 433 not vaccinated medical and non-medical HCWs from various health care facilities after the introduction of COVID-19 vaccination in Oman were analyzed. Most of the participants were nurses (41.5\%) followed by physicians (37.5\%) and non-medical HCWs (21\%). Forty percent of HCWs were willing to uptake the COVID-19 vaccines. Physicians and male HCWs had more positive attitudes toward the COVID-19 vaccines than nurses and female HCWs. Concerns about the COVID-19 vaccines including unknown health issues, efficacy and safety were stated by the participants. Our results show a low level of willingness to uptake the COVID-19 vaccines among HCWs, an issue that must be urgently addressed.
\end{abstract}

Keywords COVID-19 $\cdot$ Vaccine $\cdot$ Health care workers $\cdot$ Oman $\cdot$ Hesitancy

\section{Introduction}

Unwillingness to uptake COVID-19 vaccines has been reported in many countries around the world and among both the public and health care professionals. In both populations, reasons for rejecting or delaying vaccine uptake include concerns about vaccine safety, skepticism about the speed of vaccine development, potential sides effects, beliefs in conspiracy theories, and pre-existing health conditions [1-4].

Faryal Khamis

Khami001@gmail.com

1 Department of Medicine, Royal Hospital, PC 111 Aseeb, PO Box 1331, Muscat, Oman

2 Department of Sociology and Rural Studies, South Dakota State University, Brookings, SD, USA

3 Psychosomatic Psychiatry, Sultan Qaboos Comprehensive Cancer Care \& Research Center, Muscat, Oman

4 Department of Psychiatry, Al Masarra Hospital, Muscat, Oman

5 Department of Nursing, Royal Hospital, Muscat, Oman

6 Department of Anesthesia and Critical Care, Royal Hospital, Muscat, Oman
HCWs play a critical role in vaccine promotion, thus expression of negative attitudes toward the COVID-19 vaccines might impact the success of COVID-19 national vaccination efforts $[1,4]$. Research on COVID-19 vaccine hesitancy among HCWs has been reported worldwide [5]. Few studies, however, has been conducted from the public and HCW's in the Arab countries of the Middle East and North Africa (MENA) region [6-8]. Studies among HCWs from this region identified several key reasons for refusing to uptake vaccines including possible sides effects, lack of sufficient data on the safety of the vaccines, and speed of vaccines development [9].

The overall goal of the current study was to identify the prevalence of COVID-19 vaccine hesitancy and factors associated with acceptance of vaccine uptake in a sample of nonvaccinated HCWs in Oman.

\section{Materials and Methods}

\subsection{Study Design and Participants}

We conducted an anonymous web-based questionnaire survey from several health care facilities from January 2021 to February 2021 to examine the impact of COVID-19 on 
HCWs in Oman. Participants received an invitation to participate in the study via hospital emails and the WhatsApp communication platform. In addition, the participants were asked to pass the invitation to their colleagues. We obtained informed consent from all participants prior to their participation. Only by reading the consent and accepting to participate, they could proceed to answer the survey questionnaire. We included all individuals aged 18 years or older, working in any health care facility and currently living in Oman.

A total of 680 responses from HCWs medical and nonmedical (such as laboratory technicians, pharmacists, and administrators) were obtained during the study duration through QuestionPro platform. For the purpose of the current study, we excluded $247 \mathrm{HCWs}$ who were vaccinated. The final analysis was carried out on 433 non-vaccinated respondents.

Ethical approval to conduct this study was granted by the Royal Hospital Research Ethics Committee in Oman (SRC\#6/2021).

\subsection{Measures}

Some of the items we used in this study were modified from previous studies on COVID-19 vaccine hesitancy [1, 4]. The questionnaire consisted of two sections.

\subsubsection{Section 1: Sociodemographic, Experience with COVID-19 and Willingness to get Vaccinated}

In the first part of the questionnaire, the participants were asked to provide some sociodemographic characteristics including: gender, age, marital status and whether they cared for COVID-19 patients. Furthermore, the were asked if they know a family member, or a colleague tested positive for COVID-19. These questions followed by the response options "yes," "no," and "not sure." Next, we asked whether they would be willing to get vaccinated if the opportunity was offered to them on the day of the survey. The response was rated on a 5-point Likert scale that ranged from "strongly disagree" to "strongly agree." A higher score indicates more willingness to get vaccinated.

\subsubsection{Section 2: Attitudes Toward COVID-19 Vaccine}

In this section we asked the respondents their perceptions of the COVID-19 vaccines using 11 supportive and positive statements toward the vaccine (e.g., all health care workers should be vaccinated against COVID-19) as well as concerns and negative statements (e.g., I think the COVID-19 vaccine might cause unknown serious health problems). All the items were rated using a 5-point Likert scale that ranged from "strongly disagree" to "strongly agree." A principal component analysis with the Promax procedure $(k=4)$ showed that the 11 items accounted for $60 \%$ of the variance in the data. The Cronbach's alpha coefficient was 0.93. A composite measure was created by taking the average of all items with high scores signifying more positive attitudes toward the COVID-19 vaccines.

\subsection{Statistical Analysis}

Demographic information for the sample and the study variables were described using means and standard deviations or frequencies and percentages. For the ease of presentation, we grouped the 5-point Likert scale responses into three response categories: agree, disagree and unsure categories. That is, strongly agree and agree responses grouped in one category, strongly disagree and disagree responses in another category and unsure responses was treated as the third category.

A one-way ANOVA was used to compare groups. A statistical significance was based on $p$ value of 0.05 . All analyses were conducted with the statistical package for the social sciences (SPSS 27) software.

\section{Results}

We analyzed data from $433 \mathrm{HCWs}$ who were not vaccinated at the time of data collection. Among the participants, $41.5 \%$ were nurses, $37.5 \%$ were physicians and $21 \%$ were non-clinical staff. The age of the participants ranged from 23 to 72 years $\left(M_{\text {age }}=39.89, S D=8.82\right)$. About $68.6 \%$ were females, $84.6 \%$ were married and $58 \%$ were non-Omani citizens. The distribution of gender by nationality showed that $76.3 \%$ of the Omani participants were females, whereas $63.3 \%$ of non-Omani were females.

About $38 \%$ of the participants had a family member who tested positive for COVID-19 and 90.5\% knew a colleague/ friend who also tested positive. The analysis by nationality showed that more Omani than non-Omani had a family member tested positive for COVID-19 (58.5\% vs. 23.3\%, $p<0.05)$. No difference was observed between Omani and non-Omani regarding knowing a colleague/friend who tested positive for COVID-19 $(p=0.21)$.

Among of the participants, $24.3 \%(n=106)$ reported that they tested positive for COVID-19 with no significant difference by nationality $(p=0.50)$. Of those who tested positive, $26.42 \%$ were physicians, $60.38 \%$ were nurses and $13.59 \%$ were the non-medical HCWs. The proportion of Omani physicians and nurses who cared for COVID-19 patients was smaller than the proportion of non-Omani counterparts ( $35.7 \%$ vs. $64.3 \%, p<0.05)$. Table 1 describes the sociodemographic characteristics of participants by nationality.

Among the 433 participants, 176 (40\%) respondents were willing to have the COVID-19 vaccine if it was provided 
Table 1 Sociodemographic characteristics of participants by nationality

\begin{tabular}{|c|c|c|c|c|c|}
\hline \multirow[t]{3}{*}{ Characteristics } & \multicolumn{4}{|c|}{ Nationality } & \multirow{3}{*}{$\begin{array}{l}\text { Total } \\
n\end{array}$} \\
\hline & \multicolumn{2}{|c|}{ Omani } & \multicolumn{2}{|c|}{ Non-Omani } & \\
\hline & $n$ & $\%$ & $n$ & $\%$ & \\
\hline \multicolumn{6}{|l|}{ Age } \\
\hline $23-29$ & 32 & 19.8 & 7 & 3.2 & 39 \\
\hline $30-39$ & 72 & 44.4 & 94 & 42.5 & 166 \\
\hline $40-49$ & 42 & 25.9 & 75 & 33.9 & 117 \\
\hline $50-59$ & 13 & 8 & 39 & 17.6 & 52 \\
\hline $60+$ & 3 & 1.9 & 6 & 2.7 & 9 \\
\hline \multicolumn{6}{|l|}{ Gender } \\
\hline Females & 142 & 76.3 & 162 & 63 & 304 \\
\hline Males & 44 & 23.7 & 95 & 37 & 139 \\
\hline \multicolumn{6}{|l|}{ Occupation } \\
\hline Physicians & 72 & 38.7 & 94 & 36.6 & 166 \\
\hline Nurses & 70 & 37.6 & 114 & 44.4 & 184 \\
\hline Others & 44 & 23.7 & 19.1 & 19.1 & 93 \\
\hline $\begin{array}{l}\text { Physicians and } \\
\text { nurses who cared } \\
\text { for COVID-19 } \\
\text { patient }\end{array}$ & 89 & 37.1 & 151 & 62.9 & 240 \\
\hline \multicolumn{6}{|c|}{ COVID-19 positive status } \\
\hline Self & 42 & 22.7 & 64 & 25.3 & 106 \\
\hline Know someone & 174 & 93.5 & 226 & 88.3 & 400 \\
\hline Family member & 103 & 57.2 & 57 & 22.5 & 160 \\
\hline $\begin{array}{l}\text { Willingness to get } \\
\text { vaccinated }\end{array}$ & 75 & 40.3 & 101 & 39.6 & 176 \\
\hline
\end{tabular}

The total might not tally because of missing data

to them on the day of the survey, while $115(26.1 \%)$ were not willing to be vaccinated and 150 (34\%) were not sure. An ANOVA test showed no significant difference on the willingness to accept the vaccine by gender $[F(1)=2.85$, $p=0.09]$, occupation [ $F(1)=0.40, p=0.67]$, or nationality $[F(1)=1.41, p=0.24]$. Figure 1 shows the willingness of the participants to get the vaccine.

Table 2 shows that the attitudes scale mean score was $3.47(S D=0.80)$. The means of all the 11 items were close to the overall scale mean expect three items. The means of "All health care workers should get the COVID-19 vaccine" and "Taken the COVID-19 vaccine is a collective action to prevent the spread of COVID-19" were above the scale mean (4.01 and 4.04, respectively), an indication of a general support for vaccination. On the other hand, the lowest mean (2.96) was for the item about the interest of pharmaceutical industry in making profit from the COVID-19 vaccines rather than the safety of the vaccines.

An ANOVA test showed male HCWs had $(M=3.64$, $S D=0.80)$ more positive attitudes toward the vaccine than females $(M=3.39, S D=0.78)$; $[F(1)=5.95, p<0.05]$. There were no differences between Omani and non-Omani physicians $[F(1)=0.28, p=0.60]$ nor between non-Omani and Omani nurses in their attitudes toward the COVID-19 vaccines $[F(1)=2.40, p=0.12]$. However, the Omani nonmedical staff expressed more negative attitudes than their counterparts $[F(1)=7.41, p<0.05]$.

\section{Discussion}

This study was conducted during the early phases of COVID-19 vaccine rollout. The acceptance rate of COVID19 vaccine among healthcare workers during the study period was $40 \%$. The acceptance rate among physicians and male HCWs was higher than nurses and female HCWs. The low acceptance rate was observed despite the significant psychological impact of the COVID-19 pandemic on HCWs in Oman, as shown in a recent study, where there was a high prevalence of stress, anxiety, and poor psychological wellbeing, especially among females, young health care workers and those who interacted with known or suspected COVID19 patients [10]. In another study, nurses, Omani nationals, and frontline HCWs were the most impacted by the global 
Fig. 1 Percentage of HCWs who agreed, disagreed or unsure with the attitudes items
Table 2 Means and standard deviations for the attitudes items

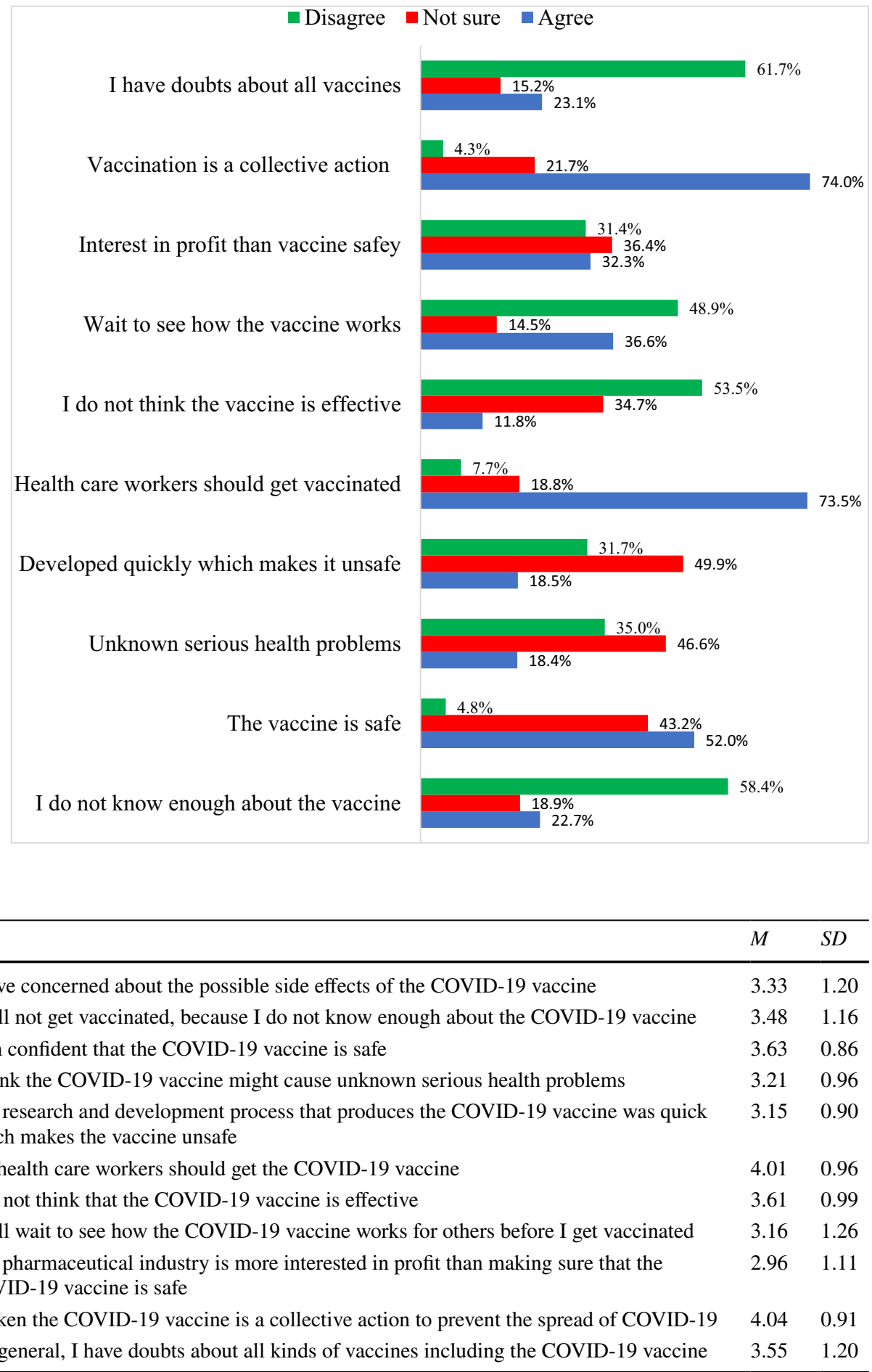

health crisis. Moreover, HCWs who cared for COVID-19 patients reported a higher stress level, lower level of wellbeing, and bad sleep quality more so in Omani than nonOmani [11].

Several vaccines have been approved for use in the Gulf Cooperate Council Countries, nevertheless vaccine hesitancy is widespread among both the public and HCWs in the region [6-9]. Concerns about the COVID-19 vaccines safety, efficacy, and adverse health outcomes were among the determinants of vaccine hesitancy $[6,9]$. In addition, the accelerated pace of vaccine development has further heightened public anxieties and affected acceptance [12]. In our study, these factors can be illustrated by the percentage of HCWs who endorsed some of the attitude's items. 
For example, four in ten said they were not sure about the vaccine safety and that the speed of the vaccine development might make it unsafe. A similar proportion of HCWs was concerned about possible future health problems associated with the vaccines. Furthermore, one-third questioned the efficiency of the vaccines. On the positive side, seven in ten agreed that vaccination is a shared responsibility and that all HCWs should be vaccinated.

In the present study, only $40 \%$ of HCWs agreed or strongly agreed that they would get a vaccine for the COVID-19 if it was offered to them on the day of the survey. Moreover, six in ten HCWs were either opposed or not sure if they would take the vaccine. This suggests that some HCWs in our cohort lack the knowledge on vaccine-preventable diseases. Research shows that vaccine acceptance among HCWs increases proportionately with their level of training on this topic $[13,14]$. Therefore, focusing interventions that address the general knowledge of HCW's on the process of vaccine production and approvals for efficiency and safety trials are inevitable to optimize the vaccine acceptance among HCW's in this region.

In this study, the acceptance rate of COVID-19 vaccination was comparable to some studies from the globe and the region that were conducted during or just before the initial vaccine rollout. For example, the acceptance rate among HCWs was 52.52\% in Saudi Arabia, SA (December 2020) [9], and 48.6\% in France and French speaking Belgium and Quebec (October-November 2020) [2]. These acceptance rates are higher than the $33.2 \%$ from SA (December-January 2020) [15], 24.5 to $36 \%$ from USA (September-October 2020) [16] and 27.7\% from the Democratic Republic of Congo (March-April 2020) [14] but lower than the 64.9\% reported acceptance rate from SA (October-November 2020) [17], 60-90\% among physicians in Greece (February 2020) and 60\% from the nurses in Hong Kong, China (February-March 2020) [18].

Similar to other studies [9, 13-18], male HCWs had more positive attitudes than female HCWs and physicians had more positive attitudes toward the COVID-19 vaccines compared to nurses $[9,13-17]$. This result is mystifying considering that more nurses in this study tested positive for COVID-19 (35.4\%) compared to physicians (17.1\%). However, this puzzle might be explained by a recent data that showed although the rate of infection among women and nurses was higher than men and physicians, the rate of death was higher among men and physicians than women and nurses [19]. In addition, risk perception is strategic for vaccine decision-making. It is possible that the perceived risk could have been lower in our cohort due to the relatively low number of confirmed cases and deaths at the time of conducting this study. On the other hand, many female HCWs were at childbearing age, and fear of vaccination side effects on future pregnancies might have played a role in vaccination hesitancy in this group. Furthermore, women tend to adopt more to the non-pharmacological interventions such as hand washing, sanitization and masking [14].

In this study, non-Omani non-medical HCWs had more positive attitudes toward the COVID-19 vaccine than their Omani counterparts. Similarly, several studies from SA have showed that expatriates were more willing for the vaccination $[15,17]$. This could be due to their limited social circle of interaction and not being influenced by the negative perception on vaccination from their relatives and friends. In addition, non-Omani non-medical HCWs might have higher trust in the health system. Numerous studies reported that a higher trust in the health system can predict vaccination acceptance [5].

The study has few limitations that warrant consideration. The data were collected using online self-report questionnaire which might be susceptible to the effect of social desirability. In addition, the research was conducted early into the vaccine rollout, where vaccine safety data were not widely available for review. Another limitation is the utilization of one item to gauge the participants' willingness to uptake the vaccine. Hence, future studies should use a composite measure based on a theoretical framework such as the theory of planned behavior.

\section{Conclusion}

COVID-19 vaccine hesitancy remains high among HCW's in Oman even after the introduction of the vaccines. Identifying the barriers to vaccination and demographic characteristics of the HCW's who refuse vaccination is essential. Interventions targeted towards increasing acceptance rates among HCW's are urgently needed.

Acknowledgements The authors would like to thank study participants for their corporation and in providing informed consent and other necessary information.

Author Contributions FK, AB and NAM participated in the study concepts and design of the study. FAL and JAN distributed and collected the data. $\mathrm{AB}$ analyzed the data. $\mathrm{FK}$ and $\mathrm{AB}$ drafted the manuscript. FAL, IAS and NAM reviewed the findings and contributed to the draft of the manuscript. MAB edited and finalized the draft. All authors reviewed, made comments and contributed to the overall study design, implementation, and draft of the manuscript. FK takes the responsibility of the integrity of the work as a whole and he is the point of correspondence.

Funding This research received no specific grant from any funding agency, commercial or not-for-profit sectors.

\section{Declarations}

Conflicts of interest The authors declare they have no conflicts of interest. 
Open Access This article is licensed under a Creative Commons Attribution 4.0 International License, which permits use, sharing, adaptation, distribution and reproduction in any medium or format, as long as you give appropriate credit to the original author(s) and the source, provide a link to the Creative Commons licence, and indicate if changes were made. The images or other third party material in this article are included in the article's Creative Commons licence, unless indicated otherwise in a credit line to the material. If material is not included in the article's Creative Commons licence and your intended use is not permitted by statutory regulation or exceeds the permitted use, you will need to obtain permission directly from the copyright holder. To view a copy of this licence, visit http://creativecommons.org/licenses/by/4.0/.

\section{References}

1. de Figueiredo A, Simas C, Karafillakis E, Paterson P, Larson HJ. Mapping global trends in vaccine confidence and investigating barriers to vaccine uptake: a large-scale retrospective temporal modelling study. Lancet. 2020;396:898-908. https://doi.org/10. 1016/S0140-6736(20)31558-0.

2. Verger P, Scronias D, Dauby N, Adedzi KA, Gobert C, Bergeat M, Gagneur A, Dubé E. Attitudes of healthcare workers towards COVID-19 vaccination: a survey in France and Frenchspeaking parts of Belgium and Canada, 2020. Eurosurveillance. 2021;26(3):2002047. https://doi.org/10.2807/1560-7917.ES.2021. 26.3.2002047.

3. Kreps S, Prasad S, Brownstein J, Hswen Y, Garibaldi B, Zhang B, Kriner D. Factors associated with US adults' likelihood of accepting COVID-19 vaccination. JAMA Netw Open. 2020;3(10):e2025594.

4. Biswas N, Mustapha T, Khubchandani J, Price J. The nature and extent of COVID-19 vaccination hesitancy in healthcare workers. J Commun Health. 2021. https://doi.org/10.1007/ s10900-021-00984-3.

5. Lazarus JV, Ratzan SC, Palayew A, Gostin LO, Larson HJ, Rabin K, Kimball S, El-Mohandes A. A global survey of potential acceptance of a COVID-19 vaccine. Nat Med. 2021;27(2):225-8. https://doi.org/10.1038/s41591-020-1124-9.

6. Al-Mohaithef M, Padhi BK. Determinants of COVID-19 vaccine acceptance in Saudi Arabia: a web-based national survey. J Multidiscip Healthc. 2020;13:1657-63. https://doi.org/10.2147/JMDH. S276771.

7. Sallam M, Dababseh D, Eid H, Al-Mahzoum K, Al-Haidar A, Taim D, et al. High rates of COVID-19 vaccine hesitancy and its association with conspiracy beliefs: a study in Jordan and Kuwait among other Arab countries. Vaccines. 2021;9(1):42.

8. Alfageeh E, Alshareef N, Angawi K, Alhazmi F, Chirwa G. Acceptability of a COVID-19 Vaccine among the Saudi population. Vaccines. 2021;9(3):226. https://doi.org/10.3390/vaccines90 30226.
9. Qattan AMN, Alshareef N, Alsharqi O, Al Rahahleh N, Chirwa GC, Al-Hanawi MK. Acceptability of a COVID-19 vaccine among healthcare workers in the Kingdom of Saudi Arabia. Front Med. 2021;8:644300. https://doi.org/10.3389/fmed.2021.644300.

10. Badahdah A, Khamis F, Al Mahyijari N, Al Balushi M, Al Hatmi H, Al Salmi I, Albulushi Z, Al NJ. The mental health of health care workers in Oman during the COVID-19 pandemic. Int J Soc Psychiatry. 2020. https://doi.org/10.1177/0020764020939596.

11. Khamis F, Al Mahyijari N, Al Lawati F, Badahdah AM. The mental health of female physicians and nurses in Oman during the COVID-19 pandemic. Oman Med J. 2020;35(6):e203. https://doi. org/10.5001/omj.2020.103.

12. Szmyd B, Karuga FF, Bartoszek A, Staniecka K, Siwecka N, Bartoszek A, Błaszczyk M, Radek M. Attitude and behaviors towards SARS-CoV-2 vaccination among healthcare workers: a cross-sectional study from Poland. Vaccines. 2021;9(3):218. https://doi.org/ 10.3390/vaccines 9030218 .

13. Marotta C, Raia DD, Ventura G, Casuccio N, Dieli F, D’Angelo $\mathrm{C}$, et al. Improvement in vaccination knowledge among health students following an integrated extra-curricular intervention, an explorative study in the University of Palermo. J Prev Med Hyg. 2017;58(2):E93-8.

14. Li M, Luo Y, Watson R, et al. Healthcare workers' (HCWs) attitudes and related factors towards COVID-19 vaccination: a rapid systematic review. Postgrad Med J. 2021. https://doi.org/10.1136/ postgradmedj-2021-140195.

15. Barry M, Temsah MH, Aljamaan F, Saddik B, Al-Eyadhy A, Alenezi S, Alamro N, Alhuzaimi AN, Alhaboob A, Alhasan K, Alsohime F, Alaraj A, Halwani R, Jamal A, Temsah O, Alzamil F, Somily A, Al-Tawfiq JA. COVID-19 vaccine uptake among healthcare workers in the fourth country to authorize BNT162b2 during the first month of rollout. Vaccine. 2021;39(40):5762-8. https://doi.org/10.1016/j.vaccine.2021.08.083.

16. Gadoth A, Halbrook M, Martin-Blais R, Gray A, Tobin NH, Ferbas $\mathrm{KG}$, et al. Cross-sectional assessment of COVID-19 vaccine acceptance among health care workers in Los Angeles. Ann Intern Med. 2021. https://doi.org/10.7326/M20-7580.

17. Elharake JA, Galal B, Alqahtani SA, Kattan RF, Barry MA, Temsah MH, Malik AA, McFadden SM, Yildirim I, Khoshnood K, Omer SB, Memish ZA. COVID-19 vaccine acceptance among health care workers in the Kingdom of Saudi Arabia. Int J Infect Dis. 2021;109:286-93. https://doi.org/10.1016/j.ijid.2021.07.004.

18. Wang MW, Wen W, Wang N, Zhou MY, Wang CY, Ni J, Jiang JJ, Zhang XW, Feng ZH, Cheng YR. COVID-19 vaccination acceptance among healthcare workers and non-healthcare workers in China: a survey. Front Public Health. 2021;2(9):709056. https:// doi.org/10.3389/fpubh.2021.709056.

19. Bandyopadhyay S, Baticulon R, Kadhum M, Alser M, Ojuka D, Badereddin Y, et al. Infection and mortality of healthcare workers worldwide from COVID-19: a systematic review. BMJ Glob Health. 2020;5(12):e003097. https://doi.org/10.1136/ bmjgh-2020-003097. 